\title{
GAMBARAN STATUS KEBERSIHAN GIGI DAN MULUT SERTA STATUS GINGIVA PADA ANAK REMAJA DI SMP ADVENT WATULANEY KABUPATEN MINAHASA
}

\author{
${ }^{1}$ Astrid M. Lesar \\ ${ }^{2}$ Damajanty H. C. Pangemanan \\ ${ }^{2}$ Kustina Zuliari
}

\author{
${ }^{1}$ Kandidat Skripsi Program Studi Pendidikan Dokter Gigi Fakultas Kedokteran \\ ${ }^{2}$ Program Studi Pendidikan Dokter Gigi Universitas Sam Ratulangi Manado \\ E-mail: astrid.fabby92@mail.com
}

\begin{abstract}
Adolescence is a transition period from childhood to adulthood characterized by the presence of physiological amendments, as well as hormonal. Such reformations may influence the hygiene of dental, mouth and gingiva. Thus are results of mental pattern, adolescents cooperation to look after dental and mouth hygiene in order to prevent gingiva's inflammation when the level of dental and mouth hygiene decreases. Gingivitis is one of periodontal diseases that is particularly vulnerable to occur during adolescence period, when dental and mouth hygiene are not carefully preserved. The purpose of this research is to identify the status of dental, mouth, and gingiva hygiene among advent junior high school adolescents in Watulaney, Regency of Minahasa. This is a descriptive study, with cross sectional study approach. Conducted in Advent Junior High School, Watulaney, Regency of Minahasa. With 63 subjects under Total Sampling method, measured by oral hygine index simplified by Green and Vermillion, and gingiva index by Loe and Sillness. The implication of this study shows that dental and mouth hygiene among adolescents overall reaches the good category obtains $14,28 \%$, medium category obtains $65,08 \%$, and poor category obtains $20,64 \%$. The status of gingiva upon general adolescents $47,62 \%$ for light inflammation, $34,92 \%$ for medium inflammation, $17,46 \%$ for severe inflammation.
\end{abstract}

Keywords: adolecents, oral hygiene status, gingival status

\begin{abstract}
Abstrak: Remaja merupakan masa transisi dari anak menuju kedewasaan yang ditandai oleh adanya perubahan fisiologis dan hormonal. Perubahan ini dapat memengaruhi kebersihan gigi dan mulut serta gingiva. Hal ini disebabkan oleh pola pemikiran, kepatuhan anak remaja terhadap kebersihan gigi dan mulut guna menjaga terjadinya peradangan pada gingiva apabila kurangnya tingkat kebersihan gigi dan mulut. Gingivitis merupakan salah satu penyakit periodontal yang sangat rentan terjadi di usia remaja apabila kebersihan gigi dan mulut tidak terjaga dengan baik. Tujuan dari penelitian ini untuk mengetahui status kebersihan gigi dan mulut serta status gingiva pada anak remaja di SMP Advent Watulaney kabupaten Minahasa. Penelitian ini merupakan penelitian deskriptif dengan pendekatan cross sectional study. Penelitian dilakukan di SMP Advent Watulaney kabupaten Minahasa dengan subjek penelitian sebanyak 63 orang, menggunakan metode Total Sampling yang diukur dengan indeks oral hygiene index simplified menurut Green and Vermillion dan indeks gingiva menurut Loe and Sillness Hasil Penelitian menunjukkan bahwa status kebersihan gigi dan mulut anak remaja berada pada kategori baik 14,28\%, kategori sedang 65,08\%, dan kategori buruk 20,64. Status gingiva anak remaja yang memiliki inflamasi ringan sebesar $47,62 \%$, inflamasi sedang sebesar $34,92 \%$, inflamasi berat sebesar $17,46 \%$.
\end{abstract}

Kata kunci: anak remaja, status kebersihan gigi dan mulut, status gingiva 
Remaja merupakan periode berakhirnya masa kanak-kanak dan datangnya awal masa kedewasaan. ${ }^{1}$ Remaja merupakan masa transisi dari anak menuju dewasa atau dikenal sebagai remaja pubertas. Dalam masa pubertas seorang anak remaja akan mengalami berbagai hal kritis dalam tumbuh kembang menuju kedewasaan sehingga memerlukan penyesuaian mental serta pembentukan sikap, nilai, serta minat. $^{1}$

Dalam pertumbuhan dan perkembangan, remaja sering mengalami masalah kesehatan, salah satunya masalah kebersihan gigi dan mulut. ${ }^{2}$ World Health Organization (WHO) merekomendasikan bahwa pelajar sekolah merupakan kelompok yang tepat untuk dilakukannya upaya promosi kesehatan dalam menjaga kesehatan rongga mulut serta jaringan disekitarnya. $^{3}$

Masalah kebersihan gigi dan mulut serta gingiva sering terjadi pada anak remaja usia 12-15 tahun. World Health Organization (WHO) merekomendasikan untuk melakukan kajian-kajian epidemiologi kesehatan gigi dan mulut pada kelompok umur 12-15 tahun, yang merupakan usia kritis untuk pengukuran indikator penyakit periodontal anak remaja sebagai usia untuk pemeriksaan, karena gigi tetap yang menjadi indeks penelitian telah seutuhnya bertumbuh. ${ }^{3}$ Kebersihan gigi dan mulut yang tidak baik dapat menyebabkan terjadinya inflamasi gingiva.

Gingiva merupakan bagian dari mukosa mulut yang menutupi mahkota gigi yang tidak tumbuh dan mengelilingi leher gigi yang sudah tumbuh, berfungsi sebagai struktur penunjang untuk jaringan di dekatnya. Gingiva dibentuk oleh jaringan berwarna merah muda pucat yang melekat dengan kokoh pada tulang dan gigi serta mukosa alveolar menyambung dengan mukogingival. $^{4}$

Beberapa studi epidemiologi menunjukan bahwa kebersihan gigi dan mulut serta status gingiva dari berbagai tingkat keparahan pada umumnya ditemukan pada anak-anak dan remaja.,
Penelitian yang dilakukan di Nigeria oleh Denloye pada remaja usia 13-15 tahun membuktikan besar debris indeks (DI) mencapai 1,57 dan besar kalkulus indeks (CI) mencapai 1,48. Dengan rata-rata Oral hygiene index simplified (OHIS) untuk lakilaki mencapai 3,09 kategori buruk, dan untuk perempuan mencapai 2,94 kategori sedang. ${ }^{7}$

Berdasarkan Riset Kesehatan Dasar (RISKESDAS) pada tahun 2013, provinsi Sulawesi Utara memiliki masalah kebersihan gigi dan mulut serta penyakit pada gingiva yaitu sebesar $31,6 \%{ }^{8}$

SMP Advent Watulaney merupakan salah satu SMP yang berada di kecamatan lembean timur kabupaten Minahasa yang belum memiliki Usaha Kesehatan Gigi Sekolah (UKGS). ${ }^{12}$ Menurut survey awal sejauh ini penelitian tentang kebersihan gigi dan mulut serta status gingiva belum pernah dilakukan di SMP Advent watulaney, juga belum mendapatkan penyuluhan tentang kebersihan gigi serta gingiva, sehingga siswa kurang memiliki pengetahuan tentang pentingnya memelihara kebersihan gigi dan mulut serta kesehatan gingiva. ${ }^{9}$

\section{BAHAN DAN METODE PENELITIAN}

Penelitian ini merupakan penelitian deskriptif dengan menggunakan desain cross sectional study. Penelitian ini dilakukan di SMP Advent Watulaney kecamatan Lembean timur kabupaten Minahasa pada bulan Juni 2015. Populasi dalam penelitian ini ialah seluruh siswa kelas 7 dan 8 yang berusia 12 sampai 15 tahun di SMP Advent Watulaney sejumlah 63 orang.

\section{HASIL PENELITIAN \\ Karakteristik Subjek Penelitian}

Berdasarkan hasil penelitian di SMP Advent Watulaney subjek yang diteliti pada penelitian ini yaitu siswa-siswi kelas 7 dan kelas 8 yang berusia 12 sampai 15 tahun. Jumlah subjek penelitian yang sesuai dengan kriteria yaitu 63 orang yang bersekolah di SMP Advent Watulaney. 
Tabel 1 menunjukkan karakteristik subjek penelitian berdasarkan usia yang terdiri dari 20 orang $(31,75 \%)$ berusia $12-$ 13 tahun, 35 orang $(55,55 \%)$ berusia $13-14$ tahun, 8 orang $(12,70 \%)$ berusia $14-15$ tahun.

Tabel 1. Distribusi subjek penelitian berdasarkan usia

\begin{tabular}{ccc}
\hline $\begin{array}{c}\text { Usia } \\
\text { (Tahun) }\end{array}$ & $\mathrm{N}$ & $\%$ \\
\hline $12-13$ & 20 & 31,75 \\
$13-14$ & 35 & 55,55 \\
$14-15$ & 8 & 12,70 \\
Total & 63 & 100 \\
\hline
\end{tabular}

Data hasil penelitian yang terlihat pada tabel 2 didapatkan dari pemeriksaan status kebersihan gigi dan mulut berdasarkan usia terlihat bahwa pada usia 12 tahun yang memiliki kebersihan gigi dan mulut pada kategori baik sebanyak 1 orang (1,59\%), kebersihan gigi dan mulut pada kategori sedang sebanyak 14 orang (22,22\%) dan kategori buruk sebanyak 5 orang (7,94\%). Pada usia 13 tahun yang memiliki kebersihan gigi dan mulut pada kategori baik sebanyak 6 orang (9,52\%), kategori sedang sebanyak 22 orang (34,92\%) dan kategori buruk sebanyak 7 orang $(11,11 \%)$. Usia 14 tahun yang memiliki kebersihan gigi dan mulut pada kategori baik sebanyak 2 orang (3,17\%), kategori sedang sebanyak 5 orang (7,94\%) dan kategori buruk sebanyak 1 orang $(1,59 \%)$.

\section{Hasil Pemeriksaan Status Kebersihan Gigi dan Mulut}

Tabel 2. Distribusi status kebersihan gigi dan mulut berdasarkan usia

\begin{tabular}{|c|c|c|c|c|c|c|c|c|}
\hline \multirow{3}{*}{$\begin{array}{c}\text { Usia } \\
\text { (Tahun) }\end{array}$} & \multicolumn{6}{|c|}{ Skor Indeks OHIS } & \multirow{2}{*}{\multicolumn{2}{|c|}{ Total }} \\
\hline & \multicolumn{2}{|c|}{ Baik } & \multicolumn{2}{|c|}{ Sedang } & \multicolumn{2}{|c|}{ Buruk } & & \\
\hline & $\mathrm{n}$ & $\%$ & $\mathrm{n}$ & $\%$ & $\mathrm{~N}$ & $\%$ & $\mathrm{~N}$ & $\%$ \\
\hline $12-13$ & 1 & 1,59 & 14 & 22,22 & 5 & 7,94 & 20 & 31,75 \\
\hline $13-14$ & 6 & 9,52 & 22 & 34,92 & 7 & 11,11 & 35 & 55,55 \\
\hline $14-15$ & 2 & 3,17 & 5 & 7,94 & 1 & 1,59 & 8 & 12,70 \\
\hline Total & 9 & 14,28 & 41 & 65,08 & 13 & 20,64 & 63 & 100 \\
\hline
\end{tabular}

Tabel 3. Distribusi status kebersihan gigi dan mulut berdasarkan jenis kelamin

\begin{tabular}{ccccccccc}
\hline Jenis & \multicolumn{8}{c}{ Status kebersihan gigi dan mulut } \\
Kelamin & Baik & $\%$ & Sedang & $\%$ & Buruk & $\%$ & n & $\%$ \\
\hline Laki-laki & 1 & 1,59 & 18 & 28,57 & 11 & 17,46 & 30 & 47,62 \\
Perempuan & 8 & 12,69 & 23 & 36,51 & 2 & 3,18 & 33 & 52,38 \\
Total & 9 & 14,28 & 41 & 65,08 & 13 & 20,64 & 63 & 100 \\
\hline
\end{tabular}

Tabel 3 menunjukkan bahwa subjek yang berjenis kelamin laki-laki yang memiliki kebersihan gigi dan mulut pada kategori baik sebanyak 1 orang (1,59\%), kategori sedang sebanyak 18 orang (28,57\%), dan kategori buruk sebanyak 11 orang $(17,46 \%)$. Sedangkan pada subjek yang berjenis kelamin perempuan yang memiliki kebersihan gigi dan mulut pada kategori baik sebanyak 8 orang (12,69\%), kategori sedang sebanyak 23 orang (36,51\%), dan kategori buruk sebanyak 2 orang (3,18\%). Secara keseluruhan subjek yang memiliki kebersihan gigi dan mulut yang baik sebanyak 9 orang (14,28\%), sedang sebanyak 41 orang (65,08\%), dan subjek yang memiliki kebersihan gigi dan mulut pada kategori buruk sebanyak 13 orang (20,64\%). 


\section{Hasil Pemeriksaan Status Gingiva}

Tabel 4. Distribusi status gingiva berdasarkan usia dan jenis kelamin

\begin{tabular}{|c|c|c|c|c|c|c|c|c|c|c|c|}
\hline \multirow{3}{*}{\multicolumn{2}{|c|}{$\begin{array}{l}\text { Usia dan } \\
\text { jenis } \\
\text { kelamin }\end{array}$}} & \multicolumn{8}{|c|}{ Status Gingiva } & \multicolumn{2}{|r|}{ Total } \\
\hline & & \multicolumn{2}{|c|}{$\begin{array}{l}\text { Inflamasi } \\
\text { ringan }\end{array}$} & \multicolumn{2}{|c|}{$\begin{array}{c}\text { Inflamasi } \\
\text { ringan }\end{array}$} & \multicolumn{2}{|c|}{$\begin{array}{l}\text { Inflamasi } \\
\text { sedang }\end{array}$} & \multicolumn{2}{|c|}{$\begin{array}{l}\text { Inflamasi } \\
\text { berat }\end{array}$} & \multirow[b]{2}{*}{$\mathrm{n}$} & \multirow[b]{2}{*}{$\%$} \\
\hline & & $\mathrm{n}$ & $\%$ & $\mathrm{n}$ & $\%$ & $\mathrm{~N}$ & $\%$ & $\mathrm{n}$ & $\%$ & & \\
\hline $\bar{L}$ & $12-13$ & 0 & 0 & 3 & 4,76 & 5 & 7,94 & 4 & 6,35 & 12 & 19,05 \\
\hline \multirow[t]{6}{*}{$\mathrm{P}$} & $13-14$ & 0 & 0 & 5 & 7,94 & 7 & 11,11 & 5 & 7,93 & 17 & 26,98 \\
\hline & $14-15$ & 0 & 0 & 0 & 0 & 1 & 1,59 & 0 & 0 & 1 & 1,59 \\
\hline & $12-13$ & 0 & 0 & 6 & 9,52 & 2 & 3,17 & 0 & 0 & 8 & 12,70 \\
\hline & $13-14$ & 0 & 0 & 12 & 19,05 & 5 & 7,94 & 1 & 1,59 & 18 & 28,57 \\
\hline & $14-15$ & 0 & 0 & 4 & 6,35 & 2 & 3,17 & 1 & 1,59 & 7 & 11,11 \\
\hline & Total & 0 & 0 & 30 & 47,62 & 22 & 34,92 & 11 & 17,46 & 63 & 100 \\
\hline
\end{tabular}

Tabel 4 menunjukkan laki-laki yang berusia 12-13 tahun paling banyak memiliki inflamasi sedang sebanyak 5 orang $(7,94 \%)$ sedangkan perempuan diusia 12-13 tahun paling banyak memiliki inflamasi ringan sebanyak 6 orang (9,52\%). Laki-laki yang berusia 13-14 tahun paling banyak memiliki inflamasi sedang sebanyak 7 orang $(11,11 \%)$ dan perempuan diusia 13-14 tahun paling banyak memilki inflamasi ringan sebanyak 12 orang (19,05\%). Laki-laki yang berusia 14-15 tahun hanya memiliki inflamasi sedang sebanyak 1 orang (1,59\%) dan perempuan di usia 14-15 tahun paling banyak memiliki inflamasi ringan sebanyak 4 orang $(6,35 \%)$.

Tabel 5. Distribusi status kebersihan gigi dan mulut berdasarkan status gingiva

\begin{tabular}{|c|c|c|c|c|c|c|c|c|c|c|}
\hline \multirow{3}{*}{$\begin{array}{c}\text { Status } \\
\text { kebersihan } \\
\text { gigi dan } \\
\text { mulut }\end{array}$} & \multicolumn{8}{|c|}{ Status gingiva } & \multirow{2}{*}{\multicolumn{2}{|c|}{ Total }} \\
\hline & \multicolumn{2}{|c|}{ Sehat } & \multicolumn{2}{|c|}{$\begin{array}{l}\text { Inflamasi } \\
\text { Ringan }\end{array}$} & \multicolumn{2}{|c|}{$\begin{array}{c}\text { Inflamasi } \\
\text { Sedang }\end{array}$} & \multicolumn{2}{|c|}{$\begin{array}{c}\text { Inflamasi } \\
\text { Berat }\end{array}$} & & \\
\hline & $\mathrm{n}$ & $\%$ & $\mathrm{n}$ & $\%$ & $\mathrm{n}$ & $\%$ & $\mathrm{n}$ & $\%$ & $\mathrm{n}$ & $\%$ \\
\hline Baik & 0 & 0 & 9 & 14,28 & 0 & 0 & 0 & 0 & 9 & 14,28 \\
\hline Sedang & 0 & 0 & 20 & 31,75 & 21 & 33,33 & 0 & 0 & 41 & 65,08 \\
\hline Buruk & 0 & 0 & 1 & 1,59 & 1 & 1,59 & 11 & 17,46 & 13 & 20,64 \\
\hline Total & 0 & 0 & 30 & 47,62 & 22 & 34,92 & 11 & 17,46 & 63 & 100 \\
\hline
\end{tabular}

Tabel 5 menunjukkan bahwa subjek yang memiliki status kebersihan gigi dan mulut yang baik, dan memiliki gingiva yang mengalami inflamasi ringan sebanyak 9 orang $(14,28 \%)$. Tidak ada subjek yang memiliki status kebersihan gigi dan mulut dalam kategori baik yang mengalami inflamasi sedang maupun berat. Subjek yang memiliki kebersihan gigi dan mulut dalam kategori sedang dan memiliki gingiva yang mengalami inflamasi ringan sebanyak 20 orang (31,75\%), subjek yang memiliki kebersihan gigi dan mulut dalam kategori sedang dan memiliki gingiva yang mengalami inflamasi sedang sebanyak 21 orang (33,33\%). Dan tidak ada subjek yang memiliki status kebersihan gigi dan mulut dalam kategori sedang yang mengalami inflamasi berat. Subjek yang memiliki kebersihan gigi dan mulut dalam kategori buruk dan memiliki gingiva yang mengalami inflamasi ringan sebanyak 1 orang $(1,59 \%)$, subjek yang memiliki kebersihan gigi dan mulut dalam kategori buruk dan memiliki gingiva yang mengalami inflamasi sedang sebanyak 1 orang $(1,59 \%)$ dan subjek yang memiliki kebersihan gigi dan mulut dalam kategori buruk dan memiliki gingiva yang mengalami inflamasi buruk sebanyak 11 
orang (17,46\%). Tidak ada subjek yang memiliki kebersihan gigi dan mulut dalam kategori baik, sedang, dan buruk yang memiliki gingiva yang sehat.

\section{BAHASAN}

Subjek yang di teliti pada penelitian ini yaitu siswa-siswa di SMP Advent Watulaney kabupaten Minahasa yang duduk di kelas 7 dan kelas 8. Usia pada sampel dalam penelitian ini yaitu 12 sampai 15 tahun. Penetapan usia yang digunakan pada penelitian ini dihitung berdasarkan terkahir kali subjek berulang tahun. ${ }^{10}$ Jumlah sampel penelitian yang memenuhi kriteria yaitu 63 orang. Hasil penelitian yang dibagi berdasarkan usia seperti yang terlihat pada tabel 5 menunjukkan bahwa sampel yang berusia 13-14 tahun memiliki jumlah terbanyak yaitu 35 orang (55,55\%), terbanyak kedua yaitu sampel yang berusia 12-13 tahun sebanyak 20 orang (31,75\%), terbanyak ketiga yaitu sampel yang berusia 14-15 tahun sebanyak 8 orang (12,70\%). Pada tabel 6 menunjukkan sampel yang paling banyak yaitu berjenis kelamin perempuan terdiri dari 33 orang (52,38\%) dan berjenis kelamin laki-laki hanya 30 orang $(47,62 \%)$.

Pada Tabel 2 dapat dilihat bahwa pada usia 12 sampai 15 tahun status kebersihan gigi dan mulut memiliki persamaan yaitu rata-rata berada pada kategori sedang dengan (skor 1,3-3,0) dengan usia diantara 12 sampai 13 tahun sebanyak 14 orang (22,22\%), usia diantara 13 sampai 14 tahun sebanyak 22 orang (34,92\%), dan usia diantara 14 sampai 15 tahun sebanyak 5 orang (7,94\%). Berdasarkan hasil penelitian status kebersihan gigi dan mulut menurut usia, usia diantara 13 sampai 14 tahun merupakan usia paling banyak dari jumlah populasi dan memiliki kriteria kebersihan gigi dan mulut rata-rata pada kategori sedang. Hasil ini sesuai dengan penelitian oleh Vyshalee L. et al yang menyatakan hampir keseluruhan siswa SMP berusia diantara 13 sampai 14 tahun, serta prevalensi kebersihan gigi dan mulut rata-rata berada pada kategori sedang sebesar $45 \%$. ${ }^{10}$ Prevalensi kebersihan gigi dan mulut mengalami sedikit penurunan pada saat pertambahan usia remaja, hal ini mungkin disebabkan oleh timbulnya kepedulian serta pengetahuan siswa dalam meningkatkan kebiasaan menyikat gigi. Hasil ini menggambarkan bahwa status kebersihan gigi dan mulut juga di pengaruhi oleh pengetahuan serta perilaku siswa dalam menjaga kebersihan gigi dan mulut.

Penelitian yang dilakukan oleh Ogunsile S tahun 2010 membuktikan perempuan memiliki kebersihan gigi dan mulut cukup baik dibandingkan laki-laki. ${ }^{11}$ Adanya perbedaan tingkat kebersihan gigi dan mulut pada siswa perempuan dan lakilaki juga terlihat di SMP Advent Watulaney menunjukkan persentase kebersihan gigi dan mulut paling banyak berada pada kategori sedang yaitu laki-laki $28,57 \%$ dan perempuan $36,51 \%$. Yang memiliki kebersihan gigi dan mulut yang baik pada perempuan sebanyak 8 orang $(12,69 \%)$ dan laki-laki hanya 1 orang (1,59\%), dan pada kategori buruk laki laki sebanyak 11 orang (17,46\%) sedangkan perempuan hanya 2 orang (3,18\%). Dengan demikian perempuan memiliki status kebersihan gigi dan mulut yang cukup baik dibandingkan laki-laki. Hal ini dilihat dari pemeriksaan lebih rendahnya debris dan kalkulus pada siswa perempuan dari pada siswa laki-laki.

Status gingiva yang diukur berdasarkan indeks gingiva menunjukkan bahwa tidak ada satupun siswa yang memiliki gingiva sehat. Persentase serta jumlah status gingiva terbanyak pada skor 0,1-1,0 yang dikategorikan mengalami inflamasi ringan yaitu sebanyak 30 orang (47,62\%), status gingiva terbanyak kedua terdapat pada kategori inflamasi sedang dengan skor 1,1-2,0 yaitu 22 orang (34,92\%), terbanyak ketiga terdapat pada kategori inflamasi berat dengan skor 2,13,0 sebanyak 11 orang (17,46\%). Hasil ini dikaitkan dengan penelitian yang dilakukan oleh Shivayogi $\mathrm{M}$ et al yang menyatakan bahwa pada anak sekolah menengah pertama tidak ada yang mempunyai gingiva sehat dan persentase status gingiva 
terbanyak mengalami inflamasi ringan yaitu rata-rata pada skor $1,2 .^{12}$

Pada Tabel 4 dapat dilihat bahwa pada usia 12 tahun paling banyak mengalami inflamasi ringan yaitu sebanyak 9 orang (14,29\%), sedangkan paling sedikit mengalami inflamasi berat yaitu hanya 4 orang $(6,35 \%)$, dan mengalami inflamasi sedang yaitu 7 orang (11,11\%). Pada usia 13 tahun paling banyak mengalami inflamasi ringan, yaitu 17 orang (26,98\%), sedangkan paling sedikit mengalami inflamasi berat yaitu hanya 6 orang (9,52\%), dan mengalami inflamasi sedang yaitu 12 orang (19,05\%). Usia 14 tahun paling banyak mengalami inflamasi ringan, yaitu 4 orang $(6,35 \%)$, sedangkan paling sedikit mengalami inflamasi berat yaitu 1 orang (1,59\%), dan subjek yang mengalami inflamasi sedang yaitu 3 orang $(4,76 \%)$.

Distribusi status gingiva jenis kelamin pada tabel 4 menunjukkan bahwa di usia diantara 12 sampai 15 tahun laki-laki dan perempuan mengalami inflamasi. Hasil ini didukung oleh penelitian Irva pada siswa SMP Negri 3 Aceh menunjukkan subjek laki-laki dan perempuan mengalami inflamasi atau gingivitis. ${ }^{13}$ Prevalensi status gingiva juga berubah disaat habisnya masa pubertas, hal ini dipengaruhi oleh teori yang menyatakan bahwa gingivitis akan berkurang sehabis masa pubertas dan berlangsung secara normal. ${ }^{14}$ Pada tabel 4 menunjukkan diusia 13-14 tahun laki-laki cenderung memiliki inflamasi sedang sebesar $11,11 \%$ sedangkan perempuan diusia 13-14 tahun cenderung memiliki inflamasi ringan sebesar 19,05\%. Lebih besarnya tingkat inflamasi pada laki-laki, karena usia 13 tahun merupakan usia awal pubertas untuk laki-laki, sedangkan perempuan memulai masa pubertas 2 tahun lebih awal dibandingkan laki-laki. ${ }^{15}$ Berkurangnya gingivitis pada masa remaja juga didukung oleh kebersihan gigi dan mulut yang baik. Pada tabel 5 menunjukkan subjek yang memiliki kebersihan gigi dan mulut yang baik memiliki inflamasi ringan sebesar (14,28\%) dan tidak memiliki inflamasi sedang maupun berat. Subjek yang memiliki kebersihan gigi dan mulut yang sedang memiliki inflamasi ringan sebesar (31,75\%), memiliki inflamasi sedang sebesar (33,33\%), dan tidak memiliki inflamasi berat. Sedangkan subjek yang memiliki kebersihan gigi dan mulut yang buruk cenderung memiliki inflamasi ringan sebesar $(1,59 \%)$, memiliki inflamasi sedang sebesar (1,59\%), dan memiliki inflamasi berat sebesar (17,46\%). Kebersihan gigi dan mulut yang tidak baik mungkin disebabkan karena sebagian besar siswa-siswi belum memahami waktu dan cara membersihkan gigi yang tepat. Selain itu ada juga yang beranggapan bisa membersihkan mulut dengan berkumur dan mengkonsumsi permen herbal.

Gingivitis pada keseluruhan siswa diduga merupakan faktor hormonal pada masa pubertas, keadaan gingiva yang tampak seperti berwarna merah, adanya edema ditandai dengan pengaruh hormon estrogen dan progesteron dalam darah. Di usia pubertas gingivitis mencapai puncaknya, peradangan lebih jelas terlihat pada usia pubertas seperti penelitian yang dilakukan oleh Lutfi L menunjukkan inflamasi cenderung sangat tinggi pada usia pubertas dibandingkan usia prapubertas karena terjadinya peningkatan hormon pada masa remaja. ${ }^{16}$ Selain faktor hormonal gingivitis juga di pengaruhi oleh kurangnya pengetahuan siswa terhadap pemeliharaan kebersihan gigi dan mulut. Hal ini dibuktikan dari hasil penelitian ini yang dilakukan di SMP Advent Watulaney menunjukkan status kebersihan gigi dan mulut berada pada kategori sedang dan status gingiva secara keseluruhan mengalami inflamasi dan tidak seorangpun yang memiliki keadaan gingiva yang sehat.

\section{SIMPULAN}

1. Status kebersihan gigi dan mulut pada anak remaja di SMP Advent Watulaney berdasarkan pengukuran indeks OHIS sebagian besar berada pada kategori sedang sebesar $65,08 \%$.

2. Status gingiva pada anak remaja di SMP Advent Watulaney berdasarkan 
pengukuran indeks gingiva sebagian besar memiliki inflamasi ringan sebesar $47,62 \%$.

\section{SARAN}

1. Bagi pemerintah khususnya dinas kesehatan diharapkan lebih meningkatkan upaya preventif dan promotif tentang kebersihan gigi dan mulut serta kesehatan gingiva, serta upaya pelaksanaan Usaha Kesehatan Gigi Sekolah (UKGS) di tingkat sekolah menengah pertama.

2. Bagi siswa SMP diharapkan dapat lebih memelihara kebersihan gigi dan mulut agar tidak memperhebat terjadinya iritasi pada gingiva selama masa pubertas dan memeriksakan kesehatan gigi dan mulut pada dokter gigi setiap 6 bulan sekali.

\section{DAFTAR PUSTAKA}

1. Juntika A, Mubiar H. Dinamika perkembangan anak dan remaja. Bandung: Refika Aditama; 2013: h.67-74

2. Hiremath SS. Textbook of preventive and community dentistry. New delhi: Elsevier. 2007; p. 128

3. World Health Organization. Important target groups. [online] 2013 [cited 2015 April 16]. Available from: URL:

http://www.who.int/oral_health/actio $\mathrm{n} / \mathrm{groups} / \mathrm{en}$

4. Itjiningsih W. Anatomi gigi. $2^{\text {nd }}$ ed. Jakarta: EGC: 2012: h.42

5. Chauan VS, Chauan RS, Devkar N, Vibhute A, More S. Gingival and periodontal disease in Children and Adolescents. Journal of Dental \& Allied Sciences 2012;1(1):26-29

6. Basuni, Cholil. D, Kania P. Gambaran indeks kebersihan mulut berdasarkan tingkat pendidikan masyarakat di desa guntung ujung kabupaten banjar. DENTINO. Jurnal kedokteran gigi 2014 Vol. 2 No.1 h. 18-23

7. Denloye. Oral hygiene status of mentally handicapped school childrenin Ibadan. Odonto-Stomatologie Tropicale. Tropical Dental Journal. Nigeria 2010; 86; p 20-21.
8. Riset kesehatan Dasar (RISKESDAS) 2013. Laporan Nasional. Departemen Kesehatan Republik Indonesia; 2013 [serial online] Available from URL: http://www.depkes.go.id/resources/do wnload/general/Hasil\%20Riskesdas\% 202013.pdf

9. Profil SMP Advent watulaney tahun 20142015

10.Karakteristik penduduk. Data statistik Indonesia: [serial online] 2013 [cited 12 juni 2015] Available From URL: http//www.datastatistikindonesia.com/portal

11.Ogusile S. Ojo I. Oral hygiene status of adolecents in a local government area of Oyo state Nigeria. Journal of Science and Technology Vol. 30 2010: p 81-85

12.Shivayogi M, Shoba D, Anand S. An Overview of Gingival and Periodontal Diseases in 12 to 15 Years using gingivitis and periodontitis site prevalence index. World Journal of Dentistry. 2011 p. 175-181

13.Irva. The Frequency of Gingival Bleeding in 12-14 years old student in SMP Negeri 3 kecamatan Baitturahman Banda Aceh. [Serial online] 2015 [cited 14 juni 2015] Available from URL: http://etd.unsyiah.ac.id/index.php?p=s how_detail\&id=11362

14.Putri MH, Herijulianti E, Nurjannah N. Ilmu pencegahan penyakit jaringan keras dan jaringan pendukung gigi. Jakarta: EGC: 2010. p. 26-35, 196-9

15.Jose B. Adolescent Development (Perkembangan Remaja) [Serial online] 2015 [cited 31 juli 2015] journal sari pediatri Vol. 12, No.1 2010 Available from URL : http://saripediatri.idai.or.id/pdfile/121-5.pdf

16.Lutfhi L, Noor H, Suyadi. Perbedaan Nilai status kesehatan Gingiva antara prapubertas di SD dengan Pubertas di SMP Ta'Mirul Islam Surakarta. [serial online] 2014 [cited 14 juni 2015] Available from URL: http://eprints.ums.ac.id/31251/9/9RR. _NASKAH_PUBLIKASI.pdf. 